\title{
La loba y la luciérnaga, La heterogeneidad del discurso poético de Rosabetty Muñoz y Sonia Caicheo
}

\author{
Yenny Ariz Castillo
}

Universidad de Concepción

\section{RESUMEN}

Análisis de los textos poéticos de Sonia C aicheo y Rosabetty M uñoz, escritoras nacidas en Chiloé. Proponemos que el discurso poético de ambas escritoras se configura como un espacio textual múltiple, heterogéneo, hecho que se relaciona con la condición - real o ficticiade sujetosmarginales y en ocasiones sujetos orales, que pertenecen y senutren de una cultura igualmente híbrida. Identificamos los elementos que conforman la heterogeneidad de esos discursos poéticos y señalamos los procedimientos recurrentes (motivos, figuras, imágenes) que los constituyen. N os apoyamos en tres conceptos teóricos: dialogismo o intertextualidad, oralidad ficticia o "recreación de la oralidad" e imaginación material. Pretendemos comprobar la relevancia que adquieren en las poéticas de Caicheo y M uñoz la materialidad del agua y de la tierra. C reemos que tanto la poesía de Sonia C aicheo como la de Rosabetty M uñoz están fuertemente vinculadas a la tierra, siendo muchas veces el elemento que las identifica.

Palabras claves Sonia Caicheo, Rosabetty M uñoz, poesía chilena, Chiloé, heterogeneidad.

\section{ABST RACT}

This article contains an analysis of the poetic texts of Sonia C aicheo and Rosabetty M uñoz, writers who were born in Chiloé. We propose that the poetic discourse of both writers is configured as a heterogeneous and multiple text which is related to the condition - real or fictitious- of marginal subjects and occasionally oral subjects who belong to and are nurtured by an equally heterogeneous culture. We identify the elements that conform the heterogeneity of these poetic discourses and indicate the recurring procedures (motives, figures, images) from which they are constituted. We support our proposal on threetheoretical concepts: dialogism or intertextuality, fictitious orality or "recreation of orality"

* Este trabajo es una adaptación de mi Tesis de M agíster en Literaturas $\mathrm{H}$ ispánicas. 
and material imagination. We propose to prove the relevance acquired by the materiality of water and earth in the poetics of $\mathrm{C}$ aicheo and $\mathrm{M}$ uñoz. We believe that the poetry of both Sonia Caicheo and Rosabetty M uñoz is strongly linked to the earth, which is often the element which identifies them.

Keywords: Sonia C aicheo, Rosabetty M uñoz, chilean poetry, Chiloé, heterogeneity.

Recibido: 01-04-2005. Aceptado: 21-09-2005.

Para mi hijita

Catalina Rocío.

\begin{abstract}
"Un escritor hacesu trabajo en horario de soledad, sin ruidos... En mi caso el tiempo más propicio es de madrugada, 0 en la nochenoche, cuando todos duermen".
\end{abstract}

Sonia Caicheo, 23 de octubre de 1996

"La poesía es una reserva donde están los mitos quevan a ser nece sarios en un determinado momento. El poeta tiene que ser un guardián del mito, aunque parezca queno dicenada para estetiempo, que es completamente desoído. Creo que todos los tiempos han sido así. Sin embargo, la poesía sigue allí, y cuando quieras recuperar los espacios sagrados allí está".

RosabetTy M UÑ OZ, 23 de noviembre de 2000

- STUDIAREM OS la obra poética de dos escritoras chilotas, vinculadas al - taller Aumen ${ }^{1}$, de Chiloé. Nos referimos a Sonia Caicheo Gallardo y Rosabetty M uñoz Serón².

$\mathrm{N}$ uestro análisis pretende comprobar que tanto la poesía de $\mathrm{C}$ aicheo ${ }^{3}$ como

${ }^{1}$ Aumen es una voz huilliche que significa "el eco de la montaña"; todavía se utiliza en al gunos lugares de C hiloé, aunque ha perdido la consonante final (aume) y significa "espíritu de los muertos que sigue rondando por las casas". Si bien comenzó como un taller literario dirigido a la comunidad escolar, muy pronto amplió sus horizontes, transformándose en el movimiento cultural más importante que haya existido en la isla de Chiloé. Asimismo, este grupo es "posiblemente el más antiguo de nuestra era post-golpe, se ha transformado en un verdadero símbolo chilote y ha esparcido poetas por casi todo el sur" (Bianchi 1990: 154).

${ }^{2}$ Ellas no pertenecieron directamente al Aumen; es decir, no participaron sistemáticamentedesus reuniones. Sin embargo, C arlosTrujillo, uno delosfundadores del grupo, expresa: “... en ellas se advierte un resultado poético similar al del grupo castreño. Su expresión es tan universalista como chilota. Ellas, además, entregan una visión de mundo desde la perspectiva femenina que en riquece su discurso poético" (Trujillo, en "H istoria de Aumen". D ocumento inédito. Archivo bibliográfico de Chiloé).

${ }^{3}$ Sonia Caicheo nació en 1943, en N ercón, Chiloé. Se vincula con Aumen el año 1977. Su obra poética se plasma fundamental mente en tres textos: Recortando sombras (Santiago, Barce lona, 1984) [Recoge poesía escrita entre los años 1980 y 1982]; Rabeles en el viento (Ancud Autoedición, 1991), Salve dolorosa (Santiago, Ediciones La M inga, 1999). Su primer trabajo de poesía fue H oras de lluvia (Puerto M ontt, M ineduc, 1977). Además ha escrito: L os que no deben morir (M inisterio de Educación, 1980) [teatro infantil]; Posdata (Concepción, 1981) 
la de $M$ uñoz ${ }^{4}$ se configuran como un espacio textual múltiple, heterogéneo, hecho que se relaciona con la condición - real o ficticia- de sujetos marginales y en ocasiones sujetos orales, que pertenecen y se nutren de una cultura igualmente híbrida. Pretendemos identificar los elementos que conforman la heterogeneidad de esos discursos poéticos y, además, señalar al gunos procedimientos recurrentes (motivos, figuras, imágenes) que los constituyen.

$\mathrm{N}$ os apoyamos en tres conceptos teóricos: el primero es el de dialogismo 0 intertextualidad, según los enfoques de M ijaíl Bajtín, Julia Kristeva, Roland Barthes y $G$ érard $G$ enette. Considerando la heterogeneidad presente en los textos de las escritoras que nos ocupan, nos parece esencial revisar los procesos de dialogismo entre diferentes textos y discursos que se producen tanto al interior de los textos poéticos, como en sus relaciones entre ellos y sus entornos ${ }^{5}$.

El segundo concepto refiere al fenómeno de "recreación de la oralidad", es decir, la utilización de elementos propios de la lengua oral en el discurso poéti$\mathrm{CO}^{6}$. L os sujetos de las obras analizadas se perciben como marginales y a la vez se inventan como sujetos orales, condición recreada, virtual, en términos de M auricio 0 stria: oralidad ficticia ${ }^{7}$. C omo sabemos, en el habla encontramos elemen-

[cuento]. Coloane, una alianza con los seres y las cosas (1989) [aproximación a ensayo]. Varios artículos en diarios La Cruz del Sur de Ancud, El Llanquihue y el Diario Austral, ambos de Puerto M ontt.

${ }^{4}$ Rosabetty M uñoz nace en Ancud, en 1960. Además de estar vinculada al grupo Aumen, perteneció al grupo C haicura, deAncud, elndice, deValdivia. 0 btuvo el Premio Pablo N eruda el año 2000. Sus textos publicados son: Canto de una oveja del rebaño (Santiago, Ediciones Ariel, 1981), En lugar de morir (Santiago, Editorial Cambio, 1986), H ijos(Valdivia, El Kultrún, 1991), Baile de señoritas (Valdivia, E ditorial El Kultrún, 1994), La Santa. H istoria de su elevación (Santiago, Ediciones Lom, 1998), Todas en mí ${ }^{4}$ (Valdivia, El Kultrún, 2000), Sombras en El Rossel ot (Santiago, Ediciones L om, 2003).

5"El significado poético remitea significadosdiscursivos distintos, de suerte queen el enunciado poético resultan legibles otros varios discursos. Se crea, así, en torno al significado poético, un espacio textual múltiple cuyos elementos son susceptibles de ser aplicados en el texto poético concreto. D enominaremos a este espacio intertextual. Tomado en la intertextualidad, el enunciado poético es un subconjunto de un conjunto mayor que es el espacio de los textos aplicados a nuestro conjunto.

En esta perspectiva, resulta claro queel significado poético no puedeser considerado como dependiente de un código único. Esel lugar donde secruzan varios códigos (al menos dos) que se hallan en relación de negación mutua"' (Kristeva, 1981²: 66-67).

${ }^{6}$ En este sentido, M artín Lienhard esboza un concepto - la escritura oralizante- para denominar "textos que recogen o reelaboran determinados elementos temáticos, enunciativos y poéticos atribuibles al discurso oral de los marginados" (Lienhard, 1995: 15).

${ }^{7} 0$ stria en uncia como una de las cuestiones generales de la problemática de la oralidad en América Latina "el referido a las diversas formas de imitación de la oralidad en textos escritos literarios (oralidad ficticia)" (0 stria, 2001: 72). 
tos sonoros quela escritura sólo puede recrear, traducir; es imposibletraspasar la palabra hablada con todos sus componentes a un texto escrito ${ }^{8}$.

Por último, utilizaremos la teoría de la imaginación material propuesta por Gastón Bachelard", quien señala la posibilidad de establecer "en el reino de la imaginación, una ley de los cuatro elementos que clasifique las diversas imaginaciones materiales según se vinculen al fuego, al aire, al agua 0 a la tierra"10. Pretendemos comprobar la relevancia que adquieren en las poéticas de $C$ aicheo y M uñoz la materialidad del agua y de la tierra, de quéforma estas materias, en términos de Bachelard, "nos trasladan su potencia onírica, una especie de solidez poética que da unidad a los verdaderos poemas"11. C reemos que, tanto la poesía de Sonia Caicheo como la de Rosabetty M uñoz están fuertemente vinculadas a la tierra, siendo muchas veces el elemento que las identifica. Por otra parte, el agua adquiere un carácter masculino, en otras ocasiones, puede remitirse a un universo de sentidos femenino/maternal, por citar dos ejemplos. Pensamos que funciona como complemento y sustento de la tierra, constituyendo a veces su maldición, otras su bendición, de tal forma que en el texto poético se trasunta la condición geográfica de C hiloé-se escribe desde un archipiélago- y su clima - caracterizado por lo lluvioso-, que, a su vez, da cuenta, en el caso de Sonia Caicheo, de la interioridad del sujeto poético.

En el estudio de los textos de M uñoz y Caicheo hemos de considerar que pertenecen a una misma generación. Ambas poetas viven la mayor parte de sus vidas en Chiloé12; su formación literaria transcurre junto al mismo grupo de poetas, Aumen; además, la situación histórica de nuestro país -época post-golpe- son factores determinantes en la escritura de sus textos. D esde una postura tradicional, en el caso de Caicheo, y transgresora e irreverente en M uñoz, sus textos son atravesados por varios discursos, siendo los más destacados el discur-

${ }^{8}$ D e esta manera "todo elemento propiamente sonoro (timbre, duración, entonación, intensidad, altura) aparecerá traspuesto en caracteres gráficos, descrito, contado, sugerido, pero jamás en su propia realidad sustancial" (0 stria, 2001: 76).

${ }^{9} \mathrm{~N}$ os apoyaremos en sus textos La poética del espacio (M éxico, Fondo de Cultura Económica, 1991) y El agua y los sueños (M éxico, Fondo de Cultura Económica, 1993).

${ }^{10}$ Bachelard 1993:10.

${ }^{11}$ Bachelard 1993: 204

${ }^{12}$ La naturaleza, la vida y la cultura de este espacio son partes esenciales de sus mundos poéticos. D ebido a esto, un sector de la crítica especializada ha catalogado su poesía como lárica: "[...] y son singulares en ella [poesía lárica] los poetas de Aumen, Renato Cárdenas (1949), Carlos Alberto Trujillo (1951), Rosabetty M uñoz (1960) y O scar Galindo (1961)" (Cameron 1988: 214). O scar G alindo (1993: 216-217) califica como un error esta calificación. Es cierto que muchos de los poetas de Aumen trabajan sobre la base de una dicotomía pasado/paraíso-presente/caos infernal. No obstante, el pasado no es propiamente un refugio, ya quelos elementos que conformaban ese pasado ya no están: la modernidad los ha destruido. 
so religioso, la oral idad y la cultura deC hiloé, queen el fondo contienea los dos primeros. Ahora bien, en los textos de Rosabetty encontramos una escritura más cercana a lo que podríamos llamar "universal", una cultura más amplia que se percibe en el vocabulario utilizado, en los procedimientos más elaborados, en al usiones a la cultura occidental. Sin embargo, en sus textos se dibuja la compleja identidad chilota con la misma intensidad que en los textos de Sonia.

El universo poético de Sonia C aicheo se nutre de la vida sencilla y cotidiana. El sujeto de los poemas se nos manifiesta desde el primer momento como una mujer que "canta" sus dolores y los de otras mujeres. A partir de la primera lectura, nos damos cuenta de que es un discurso intimista, en primer lugar, porque los motivos más importantes son el amor/desamor e historias de vida de mujeres representativas de un grupo o tipo de mujer; la hablante se refiere a ellas en forma comprensiva y empática. En segundo término, porque en el texto poético se incluye el discurso epistolar (a través de poemas-cartas, indicaciones temporales, léxico propio de este discurso) y en cierta forma el de diario de vida, por el tono de confesión que adoptan muchos textos.

Encontramos también otros tres tipos de discurso 'sincretizados' en el texto poético de Caicheo. N os referimos al relato oral, la canción popular y dostipos de discurso religioso (rezo, reescritura bíblica).

Las obras de Sonia Caicheo están influenciadas directamente por el habla de Chiloé, tanto el léxico como las estructuras sintácticas. El léxico no sólo nos remite a la oralidad, sino también al lugar desde donde se escribe: "Alguien dijo son las cinco está norteando..."13. La indeterminación del sujeto, más la forma verbal, nos recuerda una forma propia de la informal idad del discurso oral ("me dijeron", "supe por ahí", un sujeto que es nadiey a la vez es toda la comunidad); el término "norteando", propio del lenguaje popular de las zonas lluviosas ("está corriendo norte", es decir el ciel o está cubierto de nubes, lo que anuncia lluvia). EI lenguaje utilizado también nos remite a la cultura chilota en sus aspectos mítico (aves de mal augurio, por ejemplo) y religioso (los "rabeles" que lleva el viento son instrumentos de la religiosidad popular).

El discurso de la canción popular nace de la comunidad y se transmite de forma oral. Lo que Sonia Caicheo realiza en sus poemas es la re-creación de este discurso oral, oralidad ficticia. La hablante señala explícitamente en los textos finales de Rabeles en el viento y Salve D ol orosa ${ }^{14}$ que sus palabras son canciones del pueblo, de la gente y sobre todo de las mujeres. A esto se agrega la inclusión de canciones populares de C hiloée infantiles, como "La niña M aría", por ejemplo.

\footnotetext{
${ }^{13}$ RS, "27 de enero", v. 1, p. 27.

${ }^{14}$ En adelante, RV y SD, respectivamente.
} 
En el poema final de RV - "La niebla es un chal que tapa el día (para que así no digas)"- la hablante asume su poesía como un canto popular de mujeres, compuesto de todas las tradiciones que se sincretizan en Chiloé:

$$
\begin{aligned}
& \text { De otra historia cauquil } \\
& \text { justán } \quad C \text { atay! } \\
& \text { La mirada de los huilliche } \\
& \text { en los esteros de Compu } \\
& \text { Porque "el ventisquero } \\
& \text { y los años mal os"... } \\
& \text { Cantemos no más Rosario } \\
& \text { Q ue sigan los inviernos }
\end{aligned}
$$

En este fragmento se logra un efecto de oralidad utilizando léxico y formas sintácticas propias del discurso oral. Se incluyen unos versos de una canción popular (entre comillas) y se ficcionaliza un diálogo con otra "cantora" - Rosario-, de tal forma que se recrea una situación cotidiana de la comunidad en la cual la hablante de los textos se inventa como un sujeto oral, una "cantora"; los componentes fónicos de la palabra hablada son sugeridos a partir de signos de exclamación, puntos suspensivos, versos que se forman de oraciones simples y entrecortadas.

La poesía de Rosabetty M uñoz se nutre de elementos propios del lugar, como la geografía, las costumbres, los mitos, el habla. Sin embargo, contieneun acendrado propósito de buscar imágenes que desmitifiquen y a la vez reinventen el espacio chilote y el alma de todo el país. Es una escritura de versos breves, parcos, condición que se acentúa en susúltimos textos. A partir de Baile de señoritas $^{16}$ (1994), la elipsis verbal es una figura recurrente. La poeta construye sus versos elidiendo las formas verbales de "ser" o "estar", funcionen o no como auxiliares. En lo que se refiere a figuras gramaticales, observamos, además, el uso de hipérbaton y de encabalgamiento. Estaúltima es utilizada profusamente, por los que sus versos se perciben abruptos, en ocasiones, violentos, como lanzados al papel. Los versos de la mayoría de sus textos encierran una singular belleza; en cambio los poemas de La Santa manifiestan una crudeza desgarradora. Todos coinciden en ser bastante críticos de la sociedad y en profundizar en la realidad de la mujer chilena, a partir de la experiencia de la hablante, que siempre se perfila como mujer. A pesar de ello es un sujeto múltiple, ya que puede

\footnotetext{
15 "La niebla es un chal...", RV, vv. 25-32, p. 70.
}

${ }^{16} \mathrm{En}$ adelante $\mathrm{BS}$. 
adoptar el rol de santa, esposa, madre, viuda, amante, prostituta, ciudadana. Además es un sujeto situado en un sector marginal (casi siempre, Chiloé, aunque podría ser otro cualquiera).

Este C hiloé de los textos de $M$ uñoz dista mucho de la imagen romántica que sehamasificado, un lugar mágico demitos, leyendas, comidas exquisitas y música autóctona. Es todo eso, pero también puede llegar a ser un lugar oscuro, muy lejano a un paraíso. En los poemas de $M$ uñoz se reiteran las imágenes de ciudades abandonadas, destruidas o bajo un régimen injusto. La noche es, en los textos, un espacio del mal; en la noche no hay quietud, sino violencia encubierta por la oscuridad ${ }^{17}$. No obstante, las obras de Rosabetty M uñoz siempre encierran esperanzas y búsquedas de espacios de paz. Este aspecto se puede ilustrar señal ando una de las imágenes recurrentes de sus poemas: la imagen de una lámpara, siempreencendida. A pesar de la devastación y el dolor la lámpara ilumina, débilmente, pero constituye el germen de un posible cambio y de los anhelos que permanecen. Por ejemplo, cuando las mujeres esperan a los hombres que han salido a trabajar en el mar: " $\mathrm{H}$ an visto partir a sus hombres / y guardan silencio en las noches / al rededor de una lámpara"18. Las huellas de la oralidad aparecen sutilmente en sus textos. Ejemplos concretos encontramos pocos; pero más que eso nos interesa destacar el resabio de orali dad primaria ${ }^{19}$ que se percibe en su poesía.

El discurso poético de M uñoz posee un tono marcadamente profético, que atraviesa la mayoría de sus textos y que concuerda con el tono crítico de ellos. El discurso profético se construye en esencia para ser hablado o vociferado, incluso. C reemos que los textos de $M$ uñoz se relacionan intertextualmente con el texto profético bíblico, que, si bien está escrito, sus elementos constitutivos sugieren que los profetas declamaban los dichos divinos o sus visiones. Por lo tanto, la profecía - como se recrea en los textos de M uñoz- es un discurso que se conecta con la oralidad primaria ${ }^{20}$.

${ }^{17}$ La connotación del término "noche" en la poesía chilena cambia abruptamente a partir del golpe militar de 1973. Antes de este episodio se la asociaba positivamente al útero o la tierra. Posterior al '73 es una imagen de "recinto del miedo". Al respecto, ver: Alonso et al., 1989: 48.

${ }^{18} \mathrm{BS}$, “M ujerío III", p. 15.

${ }^{19}$ Término acuñado por Walter 0 ng y que se refiere a "la oralidad de una cultura que carece de todo conocimiento de la escritura o de la impresión". O ng, 1987: 20.

${ }^{20}$ I ván C arrasco califica este rasgo de la poesía de M uñoz como "religioso", delimitándolo a un sólo texto, "Eramos los elegidos", deEn lugar de morir. No obstante consideramos que el discurso profético aparece en Canto de una oveja del rebaño, En lugar de morir (anteriores al artículo de Carrasco); después se agrega H ijos y La Santa, en los cuales las profecías trasuntan en visiones que atormentan a la hablante. Esta asume ser elegida para manifestar a su colectividad "la" visión correcta sobre el devenir del pueblo, de alumbrar a los demás. 
0 tro aspecto, ya más evidente, en que se percibela oralidad, como oralidad ficticia, es en la recreación del habla popular: "La preferencia d'él era pegarme / pa' las Pascuas y los dieciochos"21. El habla informal se ficcionaliza a partir de los signos gráficos, mientras que el significado de "Pascuas" y "dieciochos" lo completa el interlocutor - si es habla real- o el lector - nuestro caso- que conoce la cultura chilena. Es decir, se afirma en el saber colectivo de una comunidad. EI término "preferencia" 'delata' el artificio de la poeta, ya que en el habla oral real es probable que se haya preferido "a él le gustaba" o "El me pegaba...", de uso más ordinario. En ocasiones, la reproducción del habla oral produce diálogos entre "personajes" del poema, lo que conecta el discurso poético con el relato: "-Vino el ángel G abriel / - Sería el padrecito nuevo / - N o es él, jmíralo! C on el brazo levantado..."22. Tal como en los relatos, el guión al comienzo de cada intervención de las mujeres sugiere el efecto de un diálogo. En otros textos encontramos derechamente la reproducción de un relato oral: "C uando el mar se llevó a sus tres hijos / ella estaba acodada en la media puerta / de su casa, pensando en ollas aladas..."23. El lenguaje metafórico de este texto revela su carácter poético ("ollas aladas"), sin embargo, se conecta con el discurso oral, tanto en la forma del discurso - comenzar con "cuando" a la manera de un relato narrado oralmente- como en las fórmulas que emplea: "... el mar se llevó" es una metáfora, pero se utiliza en el lenguaje cotidiano como eufemismo para declarar "se ahogó". O tro elemento que ayuda a producir un efecto deoralidad es la supresión de signos gráficos y el encabal gamiento: "en serio señora estuvo en clases toda / la mañana después fuimos a esperar / la micro..." "24. Lo ya mencionado, más el vocativo, los espacios del primer verso y la fórmula "en serio" propia del habla oral ordinaria, recrean el habla entrecortada, de un atribulado personaje que, por el contexto, se deduce adolescente. En otras ocasiones, la hablante se transforma en un "yo" colectivo que emula la voz de una comunidad. Además de estos aspectos, la poeta utilizaal gunas pal abras propias del habla chilota, como "cauquiles", "tejuelas" o "bordemar", por citar algunas. El habla oral, junto a otros elementos que conforman la cultura de Chiloé, permiten identificar a la escritura de Rosabetty con este lugar que, sin embargo, no se construye como texto cerrado.

Es interesante notar, con respecto a la cultura de Chiloé, la inclusión, por parte de las dos poetas, del motivo de los hombres quese van a trabajar lejos del Archipiélago, dejando a sus mujeres a merced de la soledad, el monótono paso

\footnotetext{
${ }^{21}$ LS, epígrafe a la Primera Estación. La cursiva es del texto.

22 BS, "Las ciegas", w. 6-8, p. 50.

${ }^{23} \mathrm{H}$ ijos, "N o se crían hijos para verlos morir", w. 1-3, p. 73.

${ }^{24} \mathrm{BS}$, "Castidad", vv. 1-3a, p. 41.
} 
del tiempo - que traerá la vejez y la muerte-, la tristeza y el silencio. Estas historias permiten imbricar en sus discursos poéticos el "relato oral" tan característico de Chiloé.

Los sujetos poéticos de los poemas de C aicheo y M uñoz se identifican con la tierra, seasumen parte de ella, mientras queel agua se percibe como el el emento masculino que las complementa, las fecunda, las invade o las destruye. En la poesía de Caicheo se representan los estados anímicos de la hablante y otras mujeres a través del clima o diversos elementos de la naturaleza. Este recurso se intensifica y la hablante se identifica plenamentecon árboles, la tierra o elementos marinos, mientras el amado personifica el agua. "H eredera del milagro / D e tanto correr por los inviernos [...]" (RS, "Asidero", vv. 5-6, p. 95). Estos versos contienen una metáfora en la que se sustituye el invierno por el dolor. En cambio, en los siguientes versos observamos cómo la hablante se siente parte de este espacio invernal: "D e otro invierno. Agosto puro / Tú de lluvia yo de tierra / N aceremos" (RV, "sortera", vv.14-16)25. La melancolía que se percibeen algunos poemas comprende la caída de la lluvia como marco, "el agua dulcifica un dolor[...]"26.

A parte de la configuración del espacio físico, debemos reparar en la conjunción lograda entre éste -como real-, el sueño y el tiempo. En los textos de ambas poetas se percibe una especie de (con)fusión entre la realidad y el sueño, por lo que sus versos se enmarcan en un espacio onírico, metafórico: "Un reloj marcó las trece / El mundo apresuró su ruedo..."27. Con relación al tiempo, Sonia Caicheo pareciera escribir desde un Chiloé atemporal, mientras que Rosabetty M uñoz da cuenta con angustia del inexorable paso del tiempo " $\mathrm{H}$ an sido los días el enemigo que esperaba / y me ha venido una ternura de pobre cielo..." 28 .

En cuanto al empleo del discurso religioso-bíblico, Caicheo lo incluye desde una perspectiva convencional. Considerando quela cultura chilota está tremendamente signada por lo religioso, aspecto que también es resultado de una mezcla, Sonia lo poetiza desde las costumbres de los ancestros, desde el campo y las raíces, las cantoras y rezadoras, la magia y la Biblia. Podemos percibir la búsqueda de una religiosidad apegada a los afectos y a la naturaleza. En otros términos, una religión que podríamos denominar, en una primera ap roximación, panteísta,

\footnotetext{
${ }^{25}$ Es revelador que en el plano de las ensoñaciones materiales, Bachelard identifica a la tierra como el elemento femenino y el agua como masculino.

${ }^{26}$ Bachelard, 1993: 236.

27 "M artes siete", Recortando sombras (en adelante RS), vv. 4-5, p. 42.

${ }^{28}$ ELM , "Eramos los elegidos", p. 44.
} 
que se nutre de la religión tradicional católica. Esto responde al sincretismo pagano-católico que se vive en Chiloé29.

Rosabetty, que forma parte de la misma tradición, transforma los el ementos sagrados al contemplarlos a partir de un espectro más amplio, la decadencia de toda la cultura tradicional chilota y la agonía de un país asustado. La huella de la religiosidad popular se manifiesta en los textos de M uñoz, junto a evidentes lecturas bíblicas de la poeta y la influencia que éstas ejercen en su escritura. Ejemplo de ello es la utilización de citas bíblicas como epígrafes en algunos textos, donde los versículos de la Biblia reafirman el sentido de los poemas. En el caso de ELM (1986), uno de los dos macrotextos en que se divide el libro, "Eramos los el egidos" Ileva un epígrafe del libro de Job, texto emblemático de los sufrimientos inmerecidos de un hombre: "Pero si hablo no se suaviza mi dolor / Y si callo, tampoco se aparta de mí". Justamente, los versos que se relacionan con el epígrafe se caracterizan por el desconsuelo ante el fracaso de un proyecto social, debido a la injusticia de quienes ostentan el poder.

A esto se agrega que en los poemas se percibe una relación intertextual más el aborada con los textos bíblicos, que se traduce en una apropiación de algunos conceptos de la tradición cristiana, de tal forma que su significado es negado, invertido o simplemente, transformado. Por ejemplo, la poeta acudea la figuración de la "tierra prometida" o el "paraíso" para oponerlo al entorno desolado que poetizan sus textos. Esta desolación no pasa por la natural eza del lugar -en el que reconocemos los parajes chilotes-, sino por la situación social que vive el "pueblo" que habita sus poemas. "Así, el archipiélago va quedando señalado / por viajeros intrépidos que revelan los misterios / de una tierra tan poco parecida al paraíso"30

En tercer lugar, Rosabetty M uñoz utiliza simbología religiosa para dar cuenta de la decadencia de la cultura de C hiloé. Este aspecto lo encontramos en LS (1998), texto que se apodera de una figura santificada por la igl esia católica - no se especifica cuál-, desacralizándola, pudiendo cualquier mujer transformarse en la Santa o viceversa. En algunos textos es una mujer marginal, oscura, golpeada por el marido. En otros, una mujer que experimenta placer sexual. La propia Rosabetty, al reflexionar sobre su obra, dice que es una mezcla de misticismo y paganismo. Contiene "la esperanza y sentimiento de que cualquiera

${ }^{29} \mathrm{En}$ el archipiélago se manifiesta la interacción de grupos indígenas, españoles y mestizos en la conformación de la cultura chilota. Pues bien, su condición híbrida "se manifiesta con claridad en la toponimia, en la onomástica, en los mitos, cuentos y leyendas, en ciertas formas detrabajo y entretención, como la minga y el medán, en el vestuario y en la religiosidad, entre los aspectos más significativos". Carrasco, ob. cit., p. 63.

30 "Travesía", vv. 14-16. Hijos, p. 14. 
merece el estado de elevación, no importando lo que haga en este mundo"31. En todo caso, LS se perfila como la representación del proceso de degradación dela iglesia y de la estructura social que la contiene. "Bajo las ropas sagradas / los velos se pudren / y la madera astillada / se consume" ${ }^{\prime 2}$. Por otro lado, la Santa simboliza también un tipo de mujer quela sociedad oculta y margina. "La santa orillada y lacrimosa / en un rincón de la mediagua. / Enloquecida por el olor penetrante / dela miseria"33. D esde otro punto de vista, la religión se puede leer como un motivo de su poesía, pero también como un procedimiento metafórico para aludir a un sistema social decadente.

Esprofundamenterevelador queel discurso religioso más utilizado por $\mathrm{M}$ uñoz sea el discurso profético y el de Caicheo, el rezo. Este aspecto define en gran parte sus estilos. M uñoz busca remecer, apelar a sus destinatarios; se inventa a sí misma como una vidente, capaz de conocer lo verdadero, lo justo; también se ficcionaliza como un sujeto oral y marginal -el profeta es un apartado de la sociedad- y de esta perspectiva denuncia, critica.

El primer libro de Rosabetty M uñoz, COR (1981), se configura como una visión alegórica de la sociedad chilena en el tiempo de dictadura. Para este efecto, la poeta utiliza la figuración de un rebaño de ovejas, que representa una sociedad sometida y conformista; los pastores simbolizan estructuras de poder que manejan la sociedad, rebaño. El estar dentro del rebaño equivale a aceptar de buen grado un orden establecido, mientras que apartarse del rebaño - ser oveja descarriada- es estar signado negativamente, condenado a la soledad e incomprensión, pero a cambio, los ojos son abiertos ante una realidad horren$\mathrm{da}^{34}$.

La figura de la oveja y el rebaño nos remite a tres discursos con los que dialoga el texto de M uñoz, para invertir o transformar sus sentidos a través de la ironía y de la re-semantización. En primer lugar, los cuentos infantiles, en los cuales las ovejas aparecen como seres angelicales y bondadosos; la tradición popular, que recomienda "contar ovejas" para quedarse dormido(a); y por último, el discurso bíblico, en el cual las ovejas simbolizan a los creyentes, por lo tanto, pertenecer al rebaño es estar en el "buen camino", seguir a Cristo. Las ovejas descarriadas son los pecadores, quienes deben volver al rebaño para endechar

\footnotetext{
${ }^{31}$ D iario El Llanquihue, 8 de noviembre de 1998, p. A10.

32 "La santa de terciopelo". LS, p. 45, vv. 16-19.

33 "L a santa orillada y lacrimosa". LS, p. 7, vv. 1-4

${ }^{34}$ El profesor Iván Carrasco cree ver un antecedente de esta obra en Lobos y ovejas de M anuel Silva Acevedo: "En cierta perspectiva es una continuación de L obos y ovejas (1972) de $M$ anuel Silva, al mismo tiempo que un decidido intento de reorientarlo desde una experiencia femenina de la existencia". Carrasco, Prólogo a Hijos 1991: 7.
} 
sus vidas. Rosabetty M uñoz utiliza esta terminología de forma irónica, además de cambiar el referente de estas figuras simbólicas.

El texto que inaugura el poemario dialoga con la costumbre de "contar ovejas":

Una ovejita, dos ovejitas, tres ovejitas...

Todas caen hechas polvo

al otro lado de la valla (p. 5).

La tradición de contar ovejas para dormir parte de la base que será una actividad relajante. En el texto de M uñoz, en cambio, "algo" trastoca el sueño y las dulces ovejitas son destruidas. La bucólica imagen de ensueño se transforma, entonces, en una imagen de destrucción, porque al entrar en el rebaño, las ovejas son aniquiladas. En algunos textos, el hablantelírico es una oveja descarriada que "grita"; es decir, la necesidad de expresión es urgente, apasionada, desgarrada. El discurso de la oveja descarriada es grave, dolorido, comparableal discurso bíblico profético:"H ay que salir a la calle / y zarandear a todo el mundo, / traumatizarlos si es necesario. /C ual quier cosa es mejor / que verlos bailar salsa u otro similar/ al compás de los sigl os"35. La misión de estas ovejas es convencer al mundo de lo incorrecto. La oveja descarriada-profeta desprecia el sistema imperante, aunque el precio que deba pagar sea la soledad.

En H ijos (1991) se emplea la metáfora de la maternidad para hacerse cargo dela dolorosa real idad de un país que serevela en los espacios dela noche, de los sueños y también de la vigilia.

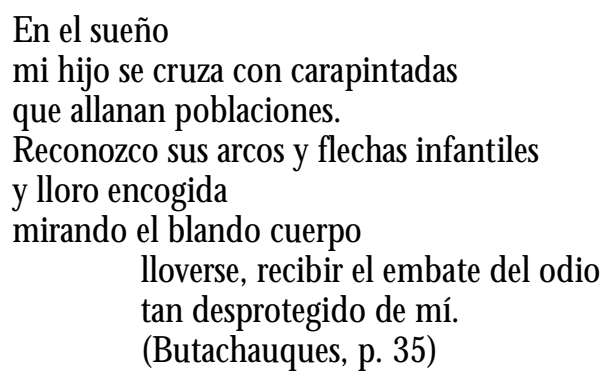

La hablantees una madre, que en el texto se vislumbra como manto protector de los hijos, ya que intenta mantenerlos alejados del odio y el dolor que rondan las calles. A su vez, los hijos se configuran como la esperanza de un cambio en la sociedad. Son seres luminosos que deben ser protegidos mientras

${ }^{35}$ COR, w. 33-38, p. 24. 
son frágiles. Si bien la maternidad puede leerse como metáfora del rol proféticoprotector que aparece en los textos de M uñoz, también es posible una lectura que privilegie la maternidad como un motivo, componente de otro aspecto fundamental de esta poesía. N os referimos a la condición social, política y cultural de la mujer en Chile.

El tono profético que acompaña y enuncia los juicios de estos textos, se manifiesta claramente en En lugar de morir (1986), libro que se divide en dos macrotextos: "La Anunciación" y "E ramos los el egidos". En toda la obra se percibe un profundo desencanto, no personal, sino colectivo. La hablante se sitúa dentro de un "nosotros" que se opone a un "ellos", quienes produjeron la debacle de un mundo feliz. Este yo colectivo se consideraba privilegiado: "Eramos los el egidos / la gran familia del pan inagotable "36. Pero "ellos" han ocasionado la pérdida de todo el bienestar. Aún aś, la hablante se percibe como privilegiada, debido a su poder de iluminar a los demás: "Fui escogida para resplandecer [...] / debo mantener la luz / en los humildes callejones de los que / odian"37.

Si en los versos de $M$ uñoz se manifiesta una aguda crítica, Sonia $C$ aicheo busca plasmar emociones, sentimientos, conmover a partir del intimismo, de la sensibilidad. Se apropia de oraciones tradicionales de la Iglesia Católica para reformularlas de acuerdo a su mundo inmediato y sus propios valores. El hecho de recrear un rezo en el texto poético es, además, otra forma de oralidad ficticia, ya que reconocemos en el rezo un tipo de discurso nacido para ser enunciado en forma oral. La oración es una súplica humilde que apela más al corazón que al entendimiento. El sujeto poético se configura como un sujeto oral, marginal - es mujer, sola y viveen una isla-, una "rezadora". Las palabras de un rezo connotan un poder especial, en tanto se dirigen a Dios, abren una puerta de comunicación entre el ser humano y la divinidad. Es también un discurso apelativo, que pide ser escuchado y respondido ${ }^{38}$.

SD es un poemario dividido en cuatro secciones-más bien estaciones- de la oración chilota "Salve D olorosa" 39 . Constituye un ruego a la Virgen de un sujeto con una clara identidad femenina. El discurso poético y el discurso religioso

\footnotetext{
36 "Eramos los elegidos", p. 24.

37 "Eramos los elegidos", p. 40.

${ }^{38}$ W olfgang Kayser clasifica a la oración como lenguaje dela canción - quese caracteriza por la "autoexpresión del estado deánimo"- en el marco de la forma dela obra lírica. Justamente es este el lenguaje que marca toda las obras de C aicheo, el de la canción, donde todo gira alrededor de las emociones de la(s) hablante(s).

39 "Salve chilota. O ración derivada deSalve cristiana universal. En Chiloé, plegaria cantada por solista y coro, a manera de responsos, en novenariosy ocasiones de dolor extremo. D irigida a la Santísima Virgen. Vigente" ("Palabras nuestras de cada día". G losario de Salve D olorosa, p. 103).
} 
se unen: es una oración a modo de poema, o un poema a modo de oración. Además, es un rezo comunitario, lo que acerca aún más este discurso a la oralidad.

Las cuatro estaciones del texto llevan por nombre fragmentos de la Salve y se estructuran en relación con un motivo predominante: Primera estación: "D ios te salve reina y madre / madre de misericordia...". Poemas sobre la muerte y el entierro del amante; Segunda estación: "D ios te salve, a ti clamamos/ los desterrados hijos de Eva". Poemas sobre mujeres; Tercera estación: "A ti suspiramos, gimiendo y llorando / en este valle de lágrimas". Poemas sobre la muerte, muje res y la modernización de C hiloé; Cuarta estación: “'Eal Pues Señora, Abogada nuestra / vuelve a nosotros / esos tus ojos misericordiosos". Poemas sobre mujeres marginales.

Como "Salve D olorosa" es una plegaria que suele cantarse en velorios, no sorprende encontrar a la muerte como motivo dominante en muchos textos. Pero lo que es más significativo es que el texto se configura como una interminable procesión de mujeres de diversa índole que lloran sus dolores, desvelos, desamparos y tristezas.

Con respecto a la utilización de procedimientos retóricos, nos parece que en Rosabetty M uñoz es dominante el uso de la ironía, al egoría, imágenes y metáfora; la poesía de Sonia Caicheo es también prolífica en imágenes y metáforas, pero creemos percibir una intención de buscar la "armonía" del texto, que en la poesía de Rosabetty no está presente. Si nos fijamos en los motivos, debemos decir que Sonia mantiene los mismos motivos en todas sus obras. Las imágenes más frecuentes se relacionan con el dolor, con los sufrimientos de las mujeres. Por ejemplo, los cuervos - que al gunas veces son "ventolera"- representan situaciones de dolor, de separación, al igual que la imagen de las "mariposas con frío": "Sus pies sellaron el barro de entrada / con esa ventolera de cuervos / que desparramó el temporal[...]"(SD "Entresueño", w. 3-5, p. 7). "Tu corazón se destapó / en la primera embestida / M ariposas con frío / Saltaron de sus aguas [...] / Y esos cuervos/ Tironeando las horas" (RV, "M alos sueños", vv. 15-18, 2223, p. 15).

L a hablante se asume resquebrajada, destrozada. Para referirse a su persona, muchas veces habla del "pájaro de escarcha": "Un pájaro de escarcha triza vientos: / Rompamos la sonrisa..." (SD , vv. 6-7, p. 19).

En relación con el amante, encontramos una sinécdoque reiterada: la sustitución de la persona del amante, por el signo, el "nombre" que lo representa, pero que nunca se menciona: "Ese nombre... / tan mal centro de tu pecho [...] / M alas lenguas lo inventaron..." (SD, "Ese nombre", vv. 1-2, 6, p. 85). 0 tra imagen referida al amante es la asociación queseconstruye entreél y el relámpa go: "Arquero de relámpagos tu corazón..." (RV, "D esertores", v. 10, p. 16). 
La sal es otro elemento que aparece asociado al dolor; se habla de "sal derramada" o de "bodas de sal" que no se pueden celebrar. Esta imagen se conecta con la creencia popular de que derramar la sal en una casa traerá mala suerte para susmoradores: " $Q Q$ ué sal oscura disuelvela mirada / y pone cataplasmas en mi boca? / ¿Dónde el nudo?" (RV, "D e Punto Cruz", vv. 17-19). Bachelard concibe la sal como una "perversión", ya que constituye la "amargura" del agua. A punta: "La sal traba una ensoñación, la ensoñación de la dulzura, una de las ensoñaciones más materiales y más naturales que existen"40.

La amargura que produce el sufrimiento se simboliza entre otras formas con una manzana camuesta, que es un tipo de "manzana dura y amarga, preferida para fabricar chicha" 41: "La carta no trae fecha / D e Río Turbio dice / M anzana camuesta el corazón / Rodando a oscuras."(RV, "posdata", vv. 22-25, p. 8).

Por último, queremos destacar el estado del insomnio como elemento re currenteque hace daño, en la medida quese configura como un espacio de dolor: "A veces / Cuando el insomnio insiste/ Reitero el único juego / Q ueen la oscuridad no tiene trampas[...]" (RS, "Puzzle", vv. 1-4, p. 47). El insomnio también se entiende como la realidad, mientras que el sueño - su contraparte- se puede asociar a dormir como a la imaginación - una "ensoñación", diría Bachelard-. A mbos aspectos aparecen en los textos asociados a los ángeles, que velan sueño o vigilia: "Un ángel de insomnio / juega a los puñales en su frente[...]" (SD , "Sólo nombre de pila", vv. 4-5, p. 41).

Rosabetty, por su parte, diversifica los motivos desus textos. La visión de un Chile en dictadura, asustado, pero sometido, mediocre y consumista, con una cultura cada vez más decadente, alterna con apariciones del amor de pareja y de Ios hijos; en esto se percibe una visión algo más optimista que en Caicheo. La preocupación por la situación dela mujer unea ambas poetas, aunqueal respecto tengan visiones distintas. M uñoz se hace cargo y problematiza roles y estereotipos femeninos. En torno a ellos, encontramos elementos socioculturales que permiten dibujarlos, por ejemplo, la subordinación de la mujer al varón, el sentimiento de marginalidad y de culpa. Estos son cuestionados a partir de diversos procedimientos, permitiendo dar a conocer alternativas ante estos estereotipos sociales.

$\mathrm{H}$ ijos se estructura en torno a un viaje, que la pareja de padres realiza junto a sus hijos desde el norte de la isla de Chiloé hasta el sur. Cada poema lleva por título el nombre de una local idad perteneciente al archipiélago y sirve de marco al universo de sentidos que crea la hablante - la madre- entre ella, sus hijos, su

\footnotetext{
${ }^{40}$ Bachelard, 1993: 235.

${ }^{41}$ En "Palabras nuestras de cada día”. G losario de SD , p. 101.
} 
pareja, el entorno, el presentey el futuro. El viaje se realiza por mar, lo que nos parece profundamente revelador si miramos este aspecto desde la teoría de la imaginación de la materia propuesta por $\mathrm{G}$ astón Bachelard en El agua y los sueños. Bachelard señala:

D e los cuatro elementos, sólo el agua puede acunar. Es el elemento acunador. Es un rasgo más de su carácter femenino: acuna como una madre [...] El agua nos lleva, nos acuna, nos adormece. El agua nos devuel ve a nuestra madre ${ }^{42}$.

Si bien es cierto que para Bachelard el agua de mar está signada por lo masculino, por el tema de las aventuras y los viajes de marineros, en el texto de Rosabetty M uñoz el mar aparece ligado a la función protectora de la madre y al aprendizaje de la vida. Los padres enseñan a navegar a sus hijos por aguas calmas y sobre todo por aguas tormentosas. El agua contiene a la familia de la misma forma que la madre contiene a los hijos, primero en su vientre y luego en sus brazos.

El elemento agua nos permite desarrollar otro aspecto dela poesía de M uñoz; nos referimos a la relación del mar y la tierra, los viajeros y las que se quedan, los esposos y las esposas. La cultura de Chiloé está determinada por el mar, de quien deriva alimentación, trabajo, mitología, por ejemplo. Es el mar quien otorga dones, pero también selleva las vidas de hijos y esposos que desaparecen, dejando a sus mujeres en soledad. Bachelard acota:

El héroe de los mares vuelve siempre de lejos; regresa del más allá; nunca habla dela orilla. El mar es fabuloso porque se expresa en primer lugar por los labios del viajero del viaje más lejano. Fabula lo lejano ${ }^{43}$.

Bachelard plantea que las historias de mar siempreson el reflejo de los viajes que los aventureros relatan. Sin embargo, en BS lo interesante no es lo que sucede en los viajes sino lo que la soledad y el silencio generan en las mujeres que se quedaron esperando. Estos textos se centran en hablar de la orilla, el discurso siempre silenciado, que a su vez está lleno de silencios. Entonces, hemos denominado historias de la orilla a aquel las que surgen durante la espera de los hombres, en soledad.

En horas de la noche

el vientre y la tetera

${ }^{42}$ Bachelard, 1993: 199-200.

${ }^{43}$ Bachelard, 1993: 231. 


\author{
son el único paisaje disponible. \\ Con hebras de colores \\ voy bordando el lienzo de la espera ${ }^{44}$
}

M ientras los varones contemplan los paisajes marinos, las mujeres contemplan los paisajes de un viaje a través del silencio y la soledad. Tal cual como Penélope, la mujer del poema, borda en espera permanente, en la noche, junto al fuego del hogar. La esposa es una figura que encarnala fidelidad, el sufrimiento en silencio por el ausente. M ujeres que bailan solas, como señala el epígrafe de G abriela M istral al inicio de BS: "La bailarina ahora está bailando / la danza del perder cuanto tenía".

El agua de mar, elemento masculino en BS, se funde con el elemento feme nino, la tierra, conectando el aspecto maternal de la mujer con el erotismo.

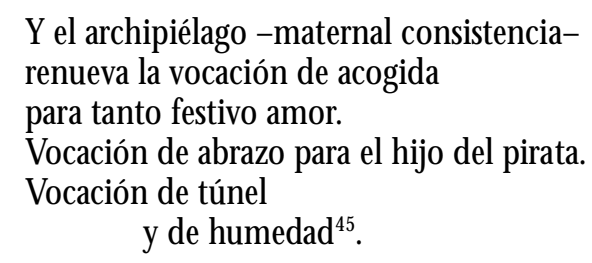

La tierra, el archipiélago de Chiloé, se presentan como una madre que acoge, madre que también es amante. Bachelard, analizando la mezcla del agua y la tierra, señala que corresponden a lo masculino y lo femenino, respectivamente, dando también una connotación erótica a esta mezcl $a^{46}$. C reemos que esa partir del erotismo que se supera el estereotipo de la esposa constante y el de la madre, figura convencionalmente asexuada. En los textos de M uñoz la mujer explora el placer, pese a que también dan cuenta de ciertos mecanismos de represión del placer femenino.

LS, texto queexplora el hibridaje cultural del archipiélago y la decadencia de sus imágenes sagradas, utiliza símbolos religiosos para construir textos que erotizan figuras sacralizadas por el cristianismo. Así el Esposo, que bíblicamente es Cristo, se encuentra con su Santa, surgiendo entre ambos un amor sexual, que resemantiza el amor espiritual y sagrado de la tradición cristiana.

Sin embargo, el placer femenino está marcado culturalmente por mecanis-

44 "Paisaje”. BS, p. 54, vv. 1-3, 9-10

45 "Bucaneros". BS, p. 19, vV. 5-10.

46 "[...] alegría varonil de penetrar en la sustancia, de palpar el interior de las sustancias, de conocer el interior de los granos, de vencer íntimamente a la tierra, como la vence el agua [...]" Bachelard 1993: 165-166. 
mos represores. Los poemas de Rosabetty M uñoz dan cuenta de ellos y deploran el efecto que causan en las mujeres: La culpa. La culpa / N os enseñan a hervir en su caldo. / N os oprime el pecho ${ }^{47}$. La posición de la hablante es de denuncia ante esta situación. La poesía, el lenguaje, permite liberar a la mujer de estas restricciones, de tal manera que el goce no sólo es legítimo en pareja, sino que también la hablante disfruta a partir de su propio cuerpo, de la autocontemplación: "D ispuesta al goce / desato el carnaval de mí"48.

Consideramos que los proyectos poéticos de las poetas difieren, aunque se nutran de los mismos elementos. M ientras la poesía de Sonia C aicheo se configura como un canto, una liturgia o un rezo que retrata el Chiloé tradicional, la poesía de Rosabetty M uñoz se imbuye de estos elementos pero para reinventar y redescubrir Chiloé en sus versos.

Ahora bien, no queremos caer en la formulación deuna dicotomía ni en una clasificación cerrada, que desconoce los matices existentes. El sujeto poético de los textos de Rosabetty conoce la angustia que la lleva a "gritar", en ocasiones, desgarradores versos, pero también la dulzura con que se arrulla un infante, lo val ioso del silencio o la condensación del discurso. Esun sujeto si emprefemenino, pero a la vez múltiple, heterogéneo, capaz de asumir diversas voces de mujeres. El sujeto de los poemas de Sonia es también mujer, pero su figura es mucho más homogénea; si bien es capaz de incluir "la historia" de varios tipos de mujeres no llega a identificarse con ellas, a asumir "su voz", de la forma que Io hace Rosabetty .

La visión profética de M uñoz, guardiana del mito y "loba" por definición propia, enuncia una poesía que contiene riesgos, fuerza y unión de muchas voces "[...] mis temores se han concentrado siempre en el peligro de vivir la medianía, en ir negociando por la vida el bienestar personal, aguando los instintos... En ese sentido, acallo la loba que contengo"49. D e Caicheo, que trabaja con "todo aquello que me conmueva" ${ }^{50}$ surge una poesía melancólica y musical, nocturna e insomne, luminosa y sombría; ella nos recuerda un pequeño ser nocturno, la luciérnaga, que trabaja mientras todos duermen, haciendo del insomnio o la vigilia un viaje, una ensoñación, una procesión de mujeres que rezan con una vela encendida.

\footnotetext{
47 "La culpa”, LS, p. 27.

48 "Agasajo", Todas en mí. Primer texto, vv. 1-2.

${ }^{49} \mathrm{G}$ onzález, $1999, \mathrm{~s} / \mathrm{p}$

${ }^{50}$ Caicheo, 1996:2.
} 


\section{BIBLIOGRAFIA}

\section{Primaria}

Caicheo, Sonia. 1984. Recortando sombras. Santiago, Chile: Barcelona. -- - - - . 1991. Rabeles en el viento. Ancud: Autoedición (Imprenta Alfa), 2a - - - - - - . 1999. Salve D olorosa. Santiago, C hile: Ediciones "La M inga".

M uñoz, Rosabetty. 1986. En lugar de morir. Santiago, C hile: Editorial Cambio.

- - . 1991. Hijos. Valdivia, Chile, Chile: El Kultrún.

— - . 1994a. Baile de señoritas. Valdivia, Chile: El Kultrún.

- - . 1994b. Canto de una oveja del rebaño. Santiago, Chile: El Kultrún².

- - . 1998. La Santa. H istoria de su elevación. Santiago, Chile: Lom.

- - . 2000. Todas en mí. Valdivia, Chile: El Kultrún.

\section{Secundaria}

Alonso, M aría N ieves. 1989. "La diáspora”, estudio introductorio a Las plumas del colibrí. Q uince años de poesía en Concepción (1973-1988), Santiago, C hile: IN PROD E/CESO C: 9-113.

Bachelard, Gastón. 1991. La poética del espacio. M éxico: Fondo de Cultura Económica. - - - - - . 1993. El agua y los sueños. M éxico, Fondo de Cultura Económica. Bianchi, Soledad. 1990. Poesía chilena. Santiago, Chile: Ediciones D ocumentas/ CESOC

Caicheo, Sonia. 1996. "Ficha biográfica". Archivo Bibliográfico de Chiloé, 23 de octubre.

Cameron, Juan. 1988. "Crónica sincrónica”, en Yamal, Ricardo, La poesía chilena actual (1960-1984) y la crítica. Concepción, C hile: Lar; 211-25.

Carrasco, Iván. 1989. "Poesía chilena de la última década (1977-1987)", Revista Chilena de Literatura 33: 31-46.

Galindo, 0 scar. 1993. "Escritura, historia, identidad: Poesía actual del sur de Chile", en Galindo, $O$ scar y D avid M iralles, Poetas actuales del sur de Chile. Antología crítica. Valdivia, C hile: Paginadura Ediciones: 203-236.

G enette, G érard. 1982. Palimpsestes. La littérature au second degré. París, Éditions du Seuil.

González C angas, Yanko. 1999. "A callo la loba que conten go". Entrevista a Rosabetty $M$ uñoz en H éroes civiles \& santos laicos. Palabra y periferia: 13 entrevistas con escritores del sur deChile. Valdivia, Chile: Editorial Barba de Palo.

Kayser, Wolfgang. 19764. Interpretación y análisis de la obra literaria. M adrid: Editorial Gredos S.A.

Kristeva, Julia. 19812. Semiótica. M adrid: Editorial Fundamentos, vol. 2.

Lienhard, M artín. 1997. "O ralidad", en M emorias de JALLA 1995 Tucumán. Facultad de Filosofía y Letras, Universidad N acional de Tucumán, vol. I, pp. 11-15.

N .N . 2000. "Rosabetty M uñoz, guardiana de los mitos de Chiloé". La Tercera, 23 de noviembre. 
Ong, Walter. 1987. O ralidad y escritura. M éxico: Fondo de Cultura Económica. O stria G onzález, M auricio. 1992. "Fundamentos lingüísticos de la intertextualidad en el discurso literario" en RLA (Revista de Lingüística Teórica y Aplicada) N ${ }^{\circ} 30$, pp. 219-229.

- - 1998-1999. "Función de la intertextualidad en la obra de Juan José Arreola", en Boletín de Filología. H omenaje a Ambrosio Rabanales. Universidad de Chile. Tomo XXXVII, p. 887-897.

- 2001. "Literatura oral, oralidad ficticia", en Estudios Filológicos N 36, pp. 71-80.

- 2002. "Poesía y oralidad", en Acta Literaria N²7, U niversidad de Concepción, pp. 67-75. 